\title{
New IGCP Projects accepted and starting in 2009
}

Project No. 571 Radon, health and natural hazards

Countries involved: Czech Republic, Finland, France, Germany, Greece, Holland, India, Indonesia/Sarawak, Iran, Israel, Nepal, Norway, Poland, Portugal, Spain, Sweden, Taiwan of China, Turkey, UK.

Full title: Radon, health and natural hazards: a global perspective

Project leaders: Prof. Gavin K. Gillmore (UK) , Dr Robin G.M. Crockett (UK), Prof. Frederic Perrier (France), Dr Tadeusz Przylibski (Poland), Dr Vivek Walia (Taiwan of China), Prof. Bikram Jit Singh Bajwa (India).

Duration: 2009-2014

Contact: Prof. Gavin K. Gillmore, Head of School, Geography, Geology and the Environment, Centre for Earth and Environmental Sciences Research (CEESR), Kingston University, Penrhyn Road, Kingston-upon-Thames, Surrey, KT1 2EE, UK. Tel: 0044 (0)20 85472000 , 0044 (0)20 85477497.

Email: G.Gillmore@kingston.ac.uk

This project will focus on a variety of impacts and hazard-associated manifestations of radon gas. This colourless, odourless, radioactive gas together with its radioactive daughter isotopes has been linked to lung cancer (and other cancers). In the UK it has been suggested by government bodies (the Health Protection Agency or HPA) that between 1000 and 2000 people die each year from radon induced lung cancer. This is not simply a UK problem: for example, the corresponding figure for the USA is 15000 22000. Recent European-wide research has demonstrated that there is no 'safe' lower limit for radon exposure, which throws into question limits set in the UK (200 Bq m-3, domestic; $400 \mathrm{~Bq} \mathrm{~m}-3$, workplace) and corresponding limits set elsewhere in Europe and the USA, for example, in the home or workplace or in drinking water before remediation is required. High/Raised radon levels have been noted in work environments (in particular water treatment plants, tunnels, caves and mines). Throughout the world links have been made between radon levels in mines and the incidence of lung cancer in mine workers, for example. Other recent research has clearly demonstrated a link between ocean and earth tides and indoor radon levels in some locations. This work is a step towards understanding the drivers behind indoor atmospheric radon concentrations, but much is still unknown. Similarly, radon is being increasingly used in the monitoring of earthquake activity: a good example is the North Anatolian Fault monitoring network recently established in Turkey but there are networks being planned in Nepal and Tibet. Radon in groundwater wells has been used to monitor such activity in Japan and Iran (the latter currently unpublished work). Understanding the behaviour and drivers of radon gas will greatly help hazard planners - both concerning radon itself and using it as an earthquake / landslide / volcanic hazard monitor and precursor.

Radon hazard assessment is a multi-/interdisciplinary subject as it requires inputs from geologists, geographers (e.g. Geographic Information Systems), mathematicians, physicists, epidemiologists/ medical researchers and planners.

This hazard has significant socioeconomic impact in the developed world and in the developing world, in terms of both indoor radon and radon-associated hazards such as earthquake activity. Short-term and long-term benefits of the programme would be to better inform decision-makers as to where and when to employ resources to minimise societal risk - both directly from radon gas and its radioactive daughter isotopes and indirectly from radon-sensitive hazards.

Project No. 574 Bending and Bent Orogens, and Continental Ribbons

Countries involved: Argentina, Australia, Canada, Germany, Italy, Mexico, New Zealand, Portugal, Romania, Russia, South Africa, Spain, Switzerland, Turkey, UK, USA.

Full title: Bending and Bent Orogens and Continental Ribbons: Implications for the Paleogeographic and Tectonic evolution of Earth, and the structure of the Lithosphere.

Project leaders: Prof. Stephen T. Johnston, (Canada), Prof. Gabriel Gutierrez-Alonso (Spain), Prof. Arlo Weil (USA).

Duration: 2009-2014

Contact: Prof. Stephen T. Johnston, School of Earth \& Ocean Sciences, University of Victoria, PO Box 3055 STN CSC, Victoria, British Columbia, Canada V8W 3P6 Email: stj@uvic.ca

Tel: 2504724481 Fax: 2507216200
Understanding how map-view bends of mountain belts form and evolve is a first order Earth System problem and is the focus of this proposal. Earth's great mountain systems, both modern and ancient, are characterized by significant map-view bends. The Bolivian bend (or Orocline) of the Andes is coincident with and formed at the same time as the Altiplano, Earth's second greatest high plateau. Significant changes in Earth's climate, including the onset of the most recent ice age, have been linked to the growth of the Altiplano. The bends (Syntaxes) adorning the western and eastern ends of the Himalaya are characterized by some of the greatest topographic relief on Earth, and are flanked by Earth's two greatest mountains, K2 and Everest, respectively. The late Paleozoic Variscan mountain system that records formation of Pangea is characterized by a $180^{\circ}$ bend in Iberian peninsula. The Iberian orocline is central and formed at the same time as a massive magmatic - thermal province that seeded much of the supercontinent with mineral deposits, and which, by weakening the crust, presaged Pangea's eventual breakup. Hence the origin and evolution of bends of mountain belts is central to Earth's climatic, topographic, and tectonic evolution. Furthermore, much of Earth's budget of mineral deposits, and its thermal evolution (and hence its potential for hydrocarbons and other energy reserves) can be related to the formation of great bends of mountain systems. An improved understanding of the processes responsible for the formation of bent mountain systems therefore promises both scientific advances, such as an improved understanding of the mechanisms and processes responsible for plate tectonics and for changes in Earth geography through time; and directly applicable societal benefits, including refined models of climate and climate evolution, and increased exploration efficiency for both mineral deposits and hydrocarbon reservoirs.

Two main research directions are apparent: (1) determining if the processes is responsible for the development of bent mountain belts, and (2) documenting the geology and evolution of specific bends. Progress in both venues is to be achieved through a series (two per year over the five year course of the project) of field-based meetings in remote, developing regions, that can provide us with access to key mountain ranges. An added benefit of this work plan will be our ability to efficiently disseminate research advances and transfer knowledge into these developing regions. Areas identified as key include: (1) Andean South America; (2) South-central Asia (Kazakhstan); (3) the Caribbean region; (4) Melanesia; (5) the Gondwanides, including Patagonia, 
the Cape belt (S. Africa) and the Tasmanides (Australia); (6) the Mediterranean-Alpine domain including the Rif of Morocco and related Betics of southern Spain, the Calabrian / Sicilian region of southern Italy, the Carpathian mountains, and the Isparta Angle (Turkey); (7) the Cordillera of western North America; and (8) the Variscides of western Europe. Results are to include the publication of field guides covering the geology of regions visited over the course of this project, refereed papers in international, high impact journals, and books published by national geological societies. The project is multidisciplinary and will involve the collection and dissemination of data spanning the fields of paleomagnetism, geochronology, structural geology, stratigraphy and sedimentology, igneous and metamorphic petrology, geochemistry, paleogeography, geophysics, paleontology, tectonics and mineral deposit studies. Direct societal benefits will include improved understanding of the geological evolution of our specific target regions, and enhanced comprehension of the links between mountain systems, mineralization and hydrocarbon reserves. In addition, our project provides numerous opportunities for the transfer of knowledge into remote and developing regions, and for the involvement and funding of young, active researchers within these regions.

\section{Project No. 580 Application of magnetic} susceptibility on Paleozoic sedimentary rocks

Countries involved: Algeria, Australia, Belgium, Brazil, Bulgaria, Canada, Czech Republic, Estonia, Iraq, Kenya, Namibia, Poland, Tunisia, USA, Vietnam.

Full title: Application of magnetic susceptibility as a paleoclimatic proxy on Paleozoic sedimentary rocks and characterization of the magnetic signal.

Project leaders: Dr. Anne-Christine da Silva (Belgium), Prof. Michael T. Whalen (USA), Prof. Jindrich Hladil (Czech Republic), Prof. Daizhao Chen (China),

Dr. Simo Spassov (Belgium), Prof. Frederic Boulvain (Belgium), Prof. Devleeschouwer Xavier (Belgium).

Duration: 2009-2014

Contact: Dr. Anne-Christine da Silva Pétrolgie sédimentaire, B20 Boulevard du Rectorat 15, Université de Liège, 4000 Liège, Belgium. Tel: 0032-43662258; Fax: 0032-43662029;

Email :ac.dasilva@ulg.ac.be

Quantitative magnetic susceptibility (MS) measurements have become widely used in the sedimentology of rocks from the Recent to the Paleozoic. The basic principle of the technique is the following: MS measurements on sedimentary rocks are considered as a proxy for impurities delivered to the sedimentary environments. Although the common sandstones or limestones have very low magnetic response, many weathering products coming from the erosion of the main land commonly have high MS values. So the measurement of MS in sediment is considered as a proxy for such detrital input. This relationship is interesting because it is hypothetized that climatic and eustatic sea level variations will affect the detrital input. A sea-level fall increases the proportion of exposed continent and siliciclastic supply and therefore increases magnetic mineral deposition. Furthermore, an increase of rainfall or a glaciation will also increase erosion. Bulk MS measurements have been used in sedimentology for correlations and for reconstruction of sea level or climatic changes. MS of Holocene, Pleistocene, and Tertiary sediments and sedimentary rocks is widely used as a paleoclimatic proxy. The use of MS in Paleozoic sediments is becoming more common but still suffers from some controversy. One of the problems is the origin of the magnetic minerals. The dominant hypothesis for sedimentologists is that magnetic minerals are mainly related to lithogenic inputs. But are these related to fluvial or eolian sources? Are these lithogenic input variations related to climatic, sea level or tectonic changes? These different influences are probably acting at different time-scales and to differentiate the different impacts, a strong interdisciplinary characterization of facies, cyclostratigraphy and the MS signal and its carriers is needed. Furthermore, considering the study of Paleozoic rocks, the influence of diagenesis in creating or destroying magnetic minerals has to be assessed. In order to solve these issues, an efficient and truly international collaboration between geoscientists from various disciplines like sedimentology, paleontology, stratigraphy, paleoclimatology, geochemistry, paleomagnetism and geophysics should be initiated and encouraged.

This project concerns three main issues. The first one consists of compiling the available MS data from the different researchers (with a main focus on the Devonian) and to continue to collect new data in the field, to test the correlative power of the technique and the influence of facies and sedimentological parameters on MS signal. The second issue is the main interdisciplinary part of the project and will focus on the identification of the origin of the MS signal. It will need a strong collaboration between sedimentologists, geophysists, magnetic properties specialists and geochemists. And the last issue will be in the light of the obtained results, to better compel the application of MS in applying MS for correlations and to reconstruct climatic variations. MS is a technique that can be performed very quickly and economically. Connected to biostratigraphy, it can be an effective and high-resolution tool for correlations. In addition, the extreme conditions and secular trends in the climate parameters of the past have also potential to contribute the research in actual climate changes. The global and interactive goal of this research could be carried on only by a worldwide network of researchers from different geoscience disciplines. Furthermore, this project can strongly benefit from the IGCP 499, which compiled abundant data and documented correlations of Devonian sections that can be used for MS measurements. The project website will be provided from Liege University network on the current MS projects as a communication platform for participants. This website will also intent to propose a list of people working in environmental MS other data which make the collaborations easier.

\section{Project No. 581 Evolution of Asian River Systems}

Countries involved: Australia, China, India, Japan, Korea, Russia, UK, USA, Vietnam.

Full title: Evolution of Asian River Systems Linking to Cenozoic Tectonics, Climate and Global Geochemical Cycles

Project leaders: Prof. Hongbo Zheng (China), Prof. Ryuji Tada (Japan), Prof. Peter Clift (UK), Dr Masood Ahmad (India), Prof. Zheng-Xiang Li (Australia), Prof. Kuo-Yen Wei (Taiwan of China).

Duration: 2009-2014

Contact: Prof. Hongbo Zheng, School of

Earth Science and Engineering, Nanjing University 22 Hankou Road, Nanjing, 210093, China Tel: +86 2583597512 , Fax: +86 2583597522

Email: zhenghb@nju.edu.cn

Most of the large rivers in Asia such as the Yangtze River, Yellow River, Indus River, Ganges/Bramaputra Rivers, Mekong and Red Rivers originate from the Himalayan-Tibet and drain large continental areas prevailed by monsoon precipitation. Therefore, the origin and nature of these large Asian rivers are highly sensitive to plateau uplift and monsoon evolution. These large drainage basins are also densely populated, and socio-economical developments in East and South Asian countries significantly depend on control and utilization of these rivers. A better understanding of the evolution of these river systems, both in recent and geological past, is beneficial not only to our knowledge about Earth dynamics, but also to social 
sustainability. Big river systems are an integral and essential part of Earth dynamics. They play significant roles in geomorphology at all scales, tectonics (erosion induced uplift and isostatic rebalancing of the crust), and filling of sedimentary basins. Most prominently, they act as the transfer of continental mass (solids and chemical compounds in solution) to the ocean, thus playing major roles in global geochemical cycles. On geological time scale, rivers' evolution involves tectonics (global and regional) and climate. Therefore, study of large river systems may hold the key to understanding of the mechanism of tectonicclimate linkage. Asia has experienced dramatic changes in both tectonics and climate during the Cenozoic. Uplift of the Tibetan Plateau is the most single event that largely shaped the landscape and drainage networks of Asia, and is attributed to have induced Asian monsoon regime and other global climatic events. However, the nature and mechanism of the linkage between each of the tectonic and monsoon evolution events still remains one of the major problems in earth science. For example, uplift of the Tibetan Plateau and surrounding ranges enhanced erosion and weathering, a process that has been hypothesized to count for the partial drawdown of $\mathrm{CO}_{2}$ and global cooling during the Cenozoic. On the other hand, the sedimentary yields of Asian rivers are by far the largest in the world owing to high erosion rate and monsoon precipitation, a process that enhances the carbon burial and causes changes in global carbon reservoir. Therefore, a full understanding of the mechanism of tectonic-climate linkage during the Cenozoic requires a comprehensive study of Asian tectonics, climate and evolution of river systems. The project plans to conduct a group effort to (1) use sedimentary archives, both onshore and offshore, to trace the evolutionary history of Asian big river systems, (2) correlate continental and marine tectonic and climatic records, in particular, those about the uplift of Tibetan Plateau and monsoonal evolution, and examine their interrelations, (3) study the sediment budget of Asian large rivers, and assess the contribution of erosion, chemical weathering and sedimentation in Asia to global carbon cycles, and (4) carry out numerical modeling to study the linking mechanism among tectonics, chemical weathering, and monsoon evolution during the Cenozoic. Through these studies, it is planned to create a new model on the tectonics and climate linkage in East Asia and their impact on global climate, and elaborate a strategy to test the model by utilizing international sediment sampling programmes such as IODP, ICDP, and IMAGES.

Project No. 582 Tropical Rivers: HydroPhysical Processes, Impacts, Hazards and Management

Countries involved: Argentina, Australia, Bolivia, Brazil, China, France, Germany, Hungary, India, Japan, Korea, Mexico, Spain, UK, USA, Venezuela.

Full title: Evolution of Asian River Systems Linking to Cenozoic Tectonics, Climate and Global Geochemical Cycles

Project leaders: Dr. Edgardo M. Latrubesse (Argentina), Prof. Rajiv Sinha (India), Dr. Jose C. Stevaux (Brazil).

Duration: 2009-2014

Contact: Edgardo M. Latrubesse, Universidad Nacional de La PlataCentro de Investigaciones GeológicasCIG, Calle 1 N0644, 1900-La Plata. Tel. 54-221-4215677; fax: 54-2214827560: Attention: At present E. Latrubese is temporarily located until May, 2009 at Department of Geological
Sciences, East Carolina UniversityECU, Room 101, Graham Building, Greenville, NC 27858, US. Tel: 252328-6360; Fax : 252-328-4391

Email: latrubesse@yahoo.com.br latrubessee@ecu.edu

Fluvial systems are considered as the economic engine in tropical regions; they have a central role in electricity production, and sustain the bulk of agricultural production and other high-value economical activities based on natural resources extraction (mining, fishing, timber). At the same time they can also be drivers of natural disasters such as floods, bank erosion and rapid channel migration. The overall scope of this project is to provide an integrated assessment of long-term direct impacts of climate variability and human-induced change and management of tropical rivers basins by identification, quantification and modeling of key hydrogeomorphologic indicators during the past and present times. The potential impacts of global change on fluvial systems and of their socio-economic implications will also be analyzed.

The most recent example of this is more than $120 \mathrm{~km}$ shift of the Kosi river in India when the new channel, $\sim 32 \mathrm{~km}$ wide carried $900,00 \mathrm{~m}^{3}$ of discharge and affected more than 500,000 people.

\section{IGCP Secretariat}

UNESCO,

Division of Ecological and Earth Sciences

1, Rue Miollis

75732 Paris Cedex 15,

France

Tel: +33145684118

Fax: +33145685822

www.unesco.org/sciencelearth

E-mail:igcp@unesco.org 